\title{
Bone mineral density in steroid-dependent asthma assessed by peripheral quantitative computed tomography
}

\author{
H. Tsugeno*, M. Nakai ${ }^{+}$, M. Okamoto*, S. Harada*, T. Mifune*, F. Mitsunobu*, K. Ashida*, \\ Y. Hosaki*, Y. Tanizaki*, T. Tsuji**
}

Bone mineral density in steroid-dependent asthma assessed by peripheral quantitative computed tomography. H. Tsugeno, M. Nakai, M. Okamoto, S. Harada, T.Mifune, F. Mitsunobu, K. Ashida, Y. Hosaki, Y. Tanizaki, T. Tsuji C ERS Journals Ltd 1999.

ABSTRACT: Chronic use of systemic glucocorticoids results in progressive bone loss and pathologic fractures. This study identified the predictive variables for bone loss and used peripheral quantitative computed tomography (pQCT) to measure changes in cortical and trabecular bone in patients receiving systemic glucocorticoid therapy of prednisone $15.4 \mathrm{~g}$.

Eighty-four asthmatic patients were included in the study. Vertebral fractures were diagnosed via plain spinal radiograms. pQCT was used to measure cortical and trabecular bone mineral density. Multiple regression analysis identified variables with predictive value.

The cumulative dose of glucocorticoid correlated with the bone mineral density $(p<0.05)$ and the trabecular bone density $(p<0.01)$. Among patients $\geq 65$ yrs of age, the cumulative dose of glucocorticoid correlated with the occurrence of vertebral fractures $(p<0.05)$, total bone mineral density $(p<0.01)$ and cortical bone mineral density $(p<0.01)$. Bone mineral density in the distal radius measured by pQCT and the vertebral bodies by axis QCT were correlated, regardless of whether systemic glucocorticoids were administered.

Glucocorticoid administration not only decreases trabecular but also cortical bone mineral density. Since cortical bone provides strength and stiffness, it appears that the loss of cortical bone is responsible for the increased incidence of fracture seen in patients receiving systemic glucocorticoid therapy.

Eur Respir J 1999; 14: 923-927.

\begin{abstract}
*Division of Medicine, ${ }^{+}$Division of Radiology, Misasa Medical Branch, Okayama University Medical School, Tottori, Japan. **First Dept of Medicine, Okayama University Medical School, Okayama, Japan.
\end{abstract}

\author{
Correspondence: H. Tsugeno \\ Division of Medicine \\ Misasa Medical Branch \\ Okayama University Medical School \\ 827 Yamada \\ Misasa \\ Tottori 682-0192 \\ Japan \\ Fax: 810858431305
}

Keywords: Bronchial asthma

cortical bone

peripheral quantitative computed tomography

systemic glucocorticoid

trabecular bone

vertebral fracture

Received: July 141998

Accepted after revision April 21999
It is well known that progressive bone loss occurs in patients receiving long-term systemic glucocorticoid (GC) therapy [1-3].

GC-induced bone loss occurs soon after therapy is initiated, in some cases within 6 months $[1,3,4]$, and bone loss $[2,4,5]$ and fractures $[1,4]$ correlate with the cumulative dose of GC. Several investigators have suggested that doses $<1,000 \mu \mathrm{g} \cdot$ day $^{-1}$ of inhaled steroid do not reduce the bone mineral density (BMD) in asthmatic patients $[6,7]$. However, some patients with severe asthma require prolonged oral systemic GC therapy. It is difficult to wean these patients off systemic GC, and these patients are at high risk for developing skeletal complications of GC therapy $[1,3-5,8,9]$.

Trabecular bone and cortical bone differ in their remodelling characteristics [10], structure [11], metabolic activity [12] and stiffness and strength [13, 14]. Trabecular bone responds more rapidly to metabolic changes caused by disease or the administration of pharmacological agents than does cortical bone [12], while cortical bone is more closely related to bone strength and stiffness $[13,14]$.

Standard densitometric methods, such as single photon absorptiometry (SPA), dual photon absorptiometry (DPA), and dual energy X-ray densitometor (DXA) give little or no information about bone quality or distribution, and do not distinguish between cortical and trabecular bone density accurately. The quantitative computed tomography (QCT) method permits the independent evaluation of cortical and trabecular bone $[15,16]$. Although some previous reports have examined vertebral bodies by axial QCT $[8,17,18]$,

Table 1. - Patient characteristics

\begin{tabular}{|c|c|c|}
\hline & $\begin{array}{l}\text { All patients } \\
(\mathrm{n}=84)\end{array}$ & $\begin{array}{l}\text { Elderly patients } \\
(\geq 65 \text { yrs })(n=56)\end{array}$ \\
\hline Sex M/F & $18 / 66$ & $12 / 44$ \\
\hline Age yrs & $68 \pm 9$ & $73 \pm 5$ \\
\hline Height $\mathrm{cm}$ & $151.2 \pm 7.9$ & $150.9 \pm 8.2$ \\
\hline Weight $\mathrm{kg}$ & $53.4 \pm 9.7$ & $51.4 \pm 8.0$ \\
\hline $\mathrm{BMI} \mathrm{kg} \cdot \mathrm{m}^{-2}$ & $23.3 \pm 3.6$ & $22.6 \pm 2.9$ \\
\hline Total BMD $\mathrm{mg} \cdot \mathrm{cm}^{-3}$ & $305.1 \pm 74.9$ & $285.2 \pm 65.3$ \\
\hline Trabecular BMD $\mathrm{mg} \cdot \mathrm{cm}^{-3}$ & $125.1 \pm 53.7$ & $117.8 \pm 48.4$ \\
\hline Cortical BMD $\mathrm{mg} \cdot \mathrm{cm}^{-3}$ & $1081.2 \pm 62.9$ & $1063.9 \pm 60.1$ \\
\hline $\begin{array}{l}\text { Number of } \\
\text { vertebral fractures }\end{array}$ & $0.57 \pm 0.95$ & $0.73 \pm 1.02$ \\
\hline $\begin{array}{l}\text { Continuous systemic } \\
\text { steroids use/nonuse }\end{array}$ & $49 / 35$ & $28 / 28$ \\
\hline $\begin{array}{l}\text { Cumulative dose } \\
\text { of prednisolone } \mathrm{g}\end{array}$ & $15.4 \pm 26.7$ & $11.2 \pm 18.7$ \\
\hline
\end{tabular}

Values are presented as an absolute number or the mean $\pm \mathrm{SD}$. BMI: body mass index; BMD: bone mineral density. 
Table 2. - Comparison of bone mineral density (BMD) in subgroups of patients

\begin{tabular}{|c|c|c|c|c|c|c|c|c|}
\hline Index & $\begin{array}{l}\text { Total BMD } \\
\mathrm{mg} \cdot \mathrm{cm}^{-3}\end{array}$ & p-value* & $\begin{array}{c}\text { Trabecular BMD } \\
\mathrm{mg} \cdot \mathrm{cm}^{-3}\end{array}$ & p-value* & $\begin{array}{l}\text { Cortical BMD } \\
\mathrm{mg} \cdot \mathrm{cm}^{-3}\end{array}$ & p-value* & $\begin{array}{l}\text { Vertebral } \\
\text { fractures }\end{array}$ & p-value* \\
\hline \multicolumn{9}{|l|}{$\mathrm{BMI} \mathrm{kg} \cdot \mathrm{m}^{-2}$} \\
\hline$\geq 23.0(n=42)$ & $319.8 \pm 71.6$ & & $128.7 \pm 53.8$ & & $1084.5 \pm 61.0$ & & $0.43 \pm 0.86$ & \\
\hline$<23.0(\mathrm{n}=42)$ & $290.4 \pm 76.0$ & NS & $121.4 \pm 54.1$ & NS & $1077.8 \pm 65.2$ & NS & $0.71 \pm 1.02$ & NS \\
\hline \multicolumn{9}{|l|}{ Age yrs } \\
\hline$\geq 65(\mathrm{n}=56)$ & $285.2 \pm 65.3$ & & $117.2 \pm 47.7$ & & $1063.9 \pm 60.1$ & & $0.73 \pm 1.02$ & \\
\hline$<65(\mathrm{n}=28)$ & $344.9 \pm 77.9$ & $\mathrm{p}<0.01$ & $142.4 \pm 62.6$ & $\mathrm{p}<0.05$ & $1116.5 \pm 53.7$ & $\mathrm{p}<0.01$ & $0.25 \pm 0.70$ & $\mathrm{p}<0.05$ \\
\hline \multicolumn{9}{|l|}{ Sex } \\
\hline Male $(\mathrm{n}=18)$ & $353.0 \pm 53.8$ & & $167.3 \pm 42.4$ & & $1122.1 \pm 51.3$ & & $0.28 \pm 0.56$ & \\
\hline Female $(n=66)$ & $292.0 \pm 74.8$ & $\mathrm{p}<0.01$ & $113.5 \pm 50.8$ & $\mathrm{p}<0.01$ & $1069.7 \pm 61.3$ & $\mathrm{p}<0.01$ & $0.65 \pm 1.03$ & NS \\
\hline \multicolumn{9}{|l|}{ Systemic steroid } \\
\hline Use $(n=49)$ & $309.5 \pm 74.6$ & & $121.7 \pm 52.2$ & & $1088.7 \pm 70.0$ & & $0.59 \pm 1.00$ & \\
\hline Nonuse $(n=35)$ & $298.9 \pm 75.9$ & NS & $129.6 \pm 56.2$ & NS & $1071.1 \pm 50.9$ & NS & $0.54 \pm 0.89$ & NS \\
\hline
\end{tabular}

Values are presented as the mean \pm SD. BMI: body mass index; NS: not significant; *: Student's t-test.

the cortical shell is extremely thin making the identification of the region of interest (ROI) imprecise [19].

Recently, improved techniques for measuring BMD have been developed. Peripheral quantitative computed tomography (pQCT) can assess the condition of bone and the risk of fracture, both clinically and as an adjunct for monitoring the effects of drug treatment [20-23]. pQCT is the only noninvasive technique for assessing BMD which measures three-dimensional density. pQCT separately determines cortical bone density and trabecular bone density with higher precision $(0.8-1.6 \%$ coefficient of variation) than axial QCT [20-23].

In the present study, the clinical characteristics associated with the development of bone loss and vertebral fractures in 84 asthmatic patients were identified. The ability of pQCT to differentiate between the effect of systemic GC administration on cortical and trabecular BMD was also studied.

While it has been reported that the trabecular bone mass of the distal radius correlates with that of the lumbar spine in healthy females $[15,24]$, this correlation has not been studied in patients at risk for GC-induced bone loss. Therefore, these two variables were also compared in asthmatic patients on high-dose GC therapy using pQCT and axial QCT $[15,24]$.

\section{Subjects and methods}

\section{Subjects}

Eighty-four outpatients with bronchial asthma (66 females and 18 males), including 56 patients $>65$ yrs old were included in the study (table 1). All patients had received inhaled GC (range: $200-800 \mu \mathrm{g} \cdot \mathrm{day}^{-1}$ beclomethasone dipropionate; mean: $332 \mu \mathrm{g} \cdot$ day $^{-1}$ ) over a period of 2-7 yrs (mean: 4.2 yrs). Forty-nine patients with steroid-dependent asthma (35 females and 14 males) received continuous oral systemic GC (mean: equivalent of 7.1 $\mathrm{mg} \cdot \mathrm{day}^{-1}$ prednisolone) over a prolonged period (mean: 8.9 yrs).

Patients receiving drugs affecting bone metabolism and patients with medical conditions affecting bone metabolism were excluded from the study. No patient had undergone treatment for osteoporosis, such as hormonal replacement. No patient had alcohol dependency or smoked. A history was taken, and a physical examination was performed on all patients. Duration, daily doses and lifetime cumulative doses of GC were calculated from medical records and patient diaries. The dose of GC is expressed in equivalent grams of prednisolone.

Within 1 week of performing pQCT, the trabecular BMD of the lumbar spine was measured by axial QCT [15, $16]$ in 29 females without vertebral deformity, including 15 patients who had received chronic systemic GC therapy (mean dose: $7.2 \mathrm{mg} \cdot$ day $^{-1}$; mean period: $8.6 \mathrm{yrs}$ ).

\section{Methods}

All patients were evaluated for the presence of vertebral deformities on lateral lumbar and thoracic radiographs. A vertebral fracture was defined by altered morphology and a decrease in vertebral height of $\sim \geq 20 \%$ at the anterior, middle or posterior aspect of the vertebral body.

pQCT was performed on the nondominant radius using a Stratec XCT 960 (Nishimoto, Tokyo, Japan) [25]. The

Table 3. - Prediction of peripheral quantitative computed tomography ( $\mathrm{pQCT}$ ) parameters by multiple regression analysis $(\mathrm{n}=84)$

\begin{tabular}{|c|c|c|c|c|c|c|c|c|c|}
\hline \multirow[b]{2}{*}{$\begin{array}{l}\text { Predictor } \\
\text { variable }\end{array}$} & \multicolumn{3}{|c|}{ Total BMD $\left(\mathrm{R}^{2}=0.491\right)$} & \multicolumn{3}{|c|}{ Trabecular BMD $\left(\mathrm{R}^{2}=0.366\right)$} & \multicolumn{3}{|c|}{ Cortical BMD $\left(\mathrm{R}^{2}=0.401\right)$} \\
\hline & $\begin{array}{l}\text { Regression } \\
\text { coefficient }\end{array}$ & SEM & p-value & $\begin{array}{l}\text { Regression } \\
\text { coefficient }\end{array}$ & SEM & p-value & $\begin{array}{l}\text { Regression } \\
\text { coefficient }\end{array}$ & SEM & p-value \\
\hline ge & -5.113 & 0.794 & $<0.0001$ & -2.502 & 0.636 & 0.0002 & -4.021 & 0.726 & $<0.0001$ \\
\hline $\mathrm{Sex}^{+}$ & -67.301 & 16.302 & $<0.0001$ & -63.112 & 13.053 & $<0.0001$ & -47.077 & 14.885 & 0.0022 \\
\hline Cumulative PSL & -0.001 & 0.0003 & 0.0182 & -0.001 & 0.0002 & 0.0023 & -0.0002 & 0.0002 & 0.2666 \\
\hline BMI & 1.829 & 1.959 & 0.3532 & 0.237 & 1.568 & 0.8803 & -0.504 & 1.797 & 0.7800 \\
\hline
\end{tabular}

BMD: bone mineral density; BMI: body mass index; PSL: prednisolone. ${ }^{+}$: Female $=1$, male $=0$. 
Table 4. - Prediction of vertebral fractures by multiple regression analysis $(n=84)$

\begin{tabular}{lccc}
\hline & \multicolumn{3}{c}{ Vertebral fractures $\left(\mathrm{R}^{2}=0.140\right)$} \\
\cline { 2 - 4 } $\begin{array}{l}\text { Predictor } \\
\text { variable }\end{array}$ & $\begin{array}{l}\text { Regression } \\
\text { coefficient }\end{array}$ & SEM & p-value \\
\hline Age & 0.034 & 0.013 & 0.0121 \\
Sex $^{+}$ & 0.456 & 0.268 & 0.932 \\
Cumulative PSL & 0.000005 & 0.141 & 0.2388 \\
BMI & -0.019 & -0.072 & 0.5541 \\
\hline
\end{tabular}

BMD: bone mineral density; BMI: body mass index; PSL: prednisolone. ${ }^{+}$: Female $=1$, male $=0$.

ultradistal radial $4 \%$ site (at $4 \%$ of the ulnar length proximal to the distal end of the radius) was used to calculate the trabecular BMD and total BMD, and the midradial $20 \%$ site was used to calculate cortical BMD. To calculate the total ROI, the software used a threshold algorithm to define the outer boundary of the bone. The trabecular ROI was generated by reducing the area of the total ROI by $45 \%$. This was performed by trimming pixels from the periphery to define a core area that consists exclusively of trabecular bone. Cortical bone was defined through a second threshold algorithm identifying high density bone in the outer rim. Constant threshold levels were used for all subjects $\left(0.5 \mathrm{mg} \cdot \mathrm{cm}^{-3}\right.$ for total bone and $0.93 \mathrm{mg} \cdot \mathrm{cm}^{-3}$ for cortical bone).

Trabecular BMD of the lumbar spine was measured by axial QCT $[15,16]$ using a Toshiba Xpeed computed tomography (CT) scanner (Toshiba, Tokyo, Japan) in 29 females within 1 week of pQCT. The average BMD from lumbar vertebrae (L)2-L4 was calculated. The BMD was expressed as $\mathrm{mg} \cdot \mathrm{cm}^{-3} \mathrm{CaCO}_{3}$ equivalent by means of a simultaneously scanned calibration phantom, B-MAS (Kyoto-Kagaku, Kyoto, Japan). The coefficient of variation $(\mathrm{CV})$ for axial QCT was 2.2\%.

\section{Statistical analysis}

Student's t-test, multiple regression analysis, and other statistical analyses were performed using the software package, StatView 4.5 (Abacus Concepts, Berkeley, CA, USA). A p-value $<0.05$ was considered significant.

\section{Results}

Multiple regression analysis was performed to determine whether two independent predictor variables, cortical BMD and trabecular BMD at the radius, correlated with the number of vertebral fractures in the 84 patients, and a highly significant relationship was demonstrated $(\mathrm{p}=$
Table 6. - Prediction of vertebral fractures by multiple regression analysis in elderly patients $(\geq 65 \mathrm{yrs}, \mathrm{n}=56$ )

\begin{tabular}{lcll}
\hline & \multicolumn{3}{c}{ Vertebral fractures $\left(\mathrm{R}^{2}=0.187\right)$} \\
\cline { 2 - 4 } $\begin{array}{l}\text { Predictor } \\
\text { variable }\end{array}$ & $\begin{array}{l}\text { Regression } \\
\text { coefficient }\end{array}$ & SEM & p-value \\
\hline Age & 0.074 & 0.031 & 0.0222 \\
Sex $^{+}$ & 0.267 & 0.345 & 0.4432 \\
Cumulative PSL & 0.00002 & 0.000008 & 0.0109 \\
BMI & 0.043 & 0.054 & 0.4212 \\
\hline
\end{tabular}

BMD: bone mineral density; BMI: body mass index; PSL: prednisolone. ${ }^{+}$: Female $=1$, male $=0$.

0.0003). Cortical BMD was found to be a significant predictor (regression coefficient $=-0.005, p=0.0002$ ) of the number of vertebral fractures, but trabecular BMD was not (regression coefficient $=-0.005, \mathrm{p}=0.187$ ).

Student's t-test was used to test for differences in total $\mathrm{BMD}$, trabecular BMD cortical BMD and the number of vertebral fractures for following clinical parameters: body mass index (BMI) $\left(\geq 23.0 \mathrm{~kg} \cdot \mathrm{m}^{-2},<23.0 \mathrm{~kg} \cdot \mathrm{m}^{-2}\right)$, age ( $\geq 65 \mathrm{yrs},<65 \mathrm{yrs}$ ), sex (male, female) and use of continuous systemic GC (use, nonuse). There were significant differences between older ( $\geq 65$ yrs) and younger patients $(<65$ $\mathrm{yrs})$, for total BMD, trabecular BMD and cortical BMD $(\mathrm{p}<0.01, \mathrm{p}<0.05$ and $\mathrm{p}<0.01$, respectively). The BMD was different between females (mean age $68 \mathrm{yrs}$ ) and males (mean age $66 \mathrm{yrs})(\mathrm{p}<0.01)$, and there were more vertebral fractures in older $(\geq 65 \mathrm{yrs})$ than younger patients $(<65 \mathrm{yrs})$ $(\mathrm{p}<0.05)$ (table 2).

Multiple regression analysis was also performed for total BMD, trabecular BMD, cortical BMD and the number of vertebral fractures to determine the predictive value at the following variables: age, lifetime cumulative dose of GC, sex (male, female) and BMI. Significant relationships were demonstrated between each of these variables and total, trabecular and cortical BMD $(\mathrm{p}<0.01)$, and the number of vertebral fractures $(\mathrm{p}<0.05)$. Age and sex had predictive value for total $\mathrm{BMD}$, trabecular $\mathrm{BMD}$, and cortical BMD $(\mathrm{p}<0.01)$ (table 3$)$. Age was an independent predictor of the number of vertebral fractures $(p<0.05)$ (table 4). Lifetime cumulative dose of GC was related to total BMD $(\mathrm{p}<0.05)$ and trabecular BMD $(\mathrm{p}<0.01)$, but not to cortical BMD (table 3 ). In patients $\geq 65$-yrs-old, all four variables predicted total, trabecular and cortical BMD $(p<0.01)$, as well as the number of vertebral fractures $(\mathrm{p}<0.05)$. Sex predicted total, trabecular, and cortical BMD $(\mathrm{p}<0.01)$. Age predicted total BMD $(\mathrm{p}<0.01)$, cortical BMD $(p<0.05)$ (table 5), and the number of vertebral fractures $(\mathrm{p}<0.05)$ (table 6$)$. The lifetime cumulative dose of $\mathrm{GC}$ was related to total BMD $(\mathrm{p}<0.01)$,

Table 5. - Prediction of peripheral quantitative computed tomography ( $\mathrm{PQCT}$ ) parameters by multiple regression analysis in elderly patients $(\geq 65 \mathrm{yrs}, \mathrm{n}=56)$

\begin{tabular}{|c|c|c|c|c|c|c|c|c|c|}
\hline \multirow[b]{2}{*}{$\begin{array}{l}\text { Predictor } \\
\text { variable }\end{array}$} & \multicolumn{3}{|c|}{ Total BMD $\left(\mathrm{R}^{2}=0.501\right)$} & \multicolumn{3}{|c|}{ Trabecular BMD $\left(\mathrm{R}^{2}=0.418\right)$} & \multicolumn{3}{|c|}{ Cortical BMD $\left(\mathrm{R}^{2}=0.403\right)$} \\
\hline & $\begin{array}{l}\text { Regression } \\
\text { coefficient }\end{array}$ & SEM & p-value & $\begin{array}{l}\text { Regression } \\
\text { coefficient }\end{array}$ & SEM & p-value & $\begin{array}{l}\text { Regression } \\
\text { coefficient }\end{array}$ & SEM & $\mathrm{p}$-value \\
\hline Age & -6.470 & 1.578 & 0.0001 & -2.468 & 1.263 & 0.0562 & -5.664 & 1.590 & 0.0008 \\
\hline $\mathrm{Sex}^{+}$ & -65.556 & 17.376 & 0.0002 & -66.002 & 13.912 & $<0.0001$ & -49.244 & 17.514 & 0.0070 \\
\hline Cumulative PSL & -0.001 & 0.0004 & 0.0065 & -0.0004 & 0.0003 & 0.1498 & -0.001 & 0.0004 & 0.0020 \\
\hline BMI & 0.296 & 2.698 & 0.9130 & 1.342 & 2.160 & 0.5372 & -3.365 & 2.716 & 0.2211 \\
\hline
\end{tabular}

BMD: bone mineral density; BMI: body mass index; PSL: prednisolone. ${ }^{+}$: Female $=1$, male $=0$. 
cortical BMD $(\mathrm{p}<0.01)$ (table 5), and the number of vertebral fractures $(\mathrm{p}<0.05)$ (table 6$)$.

The QCT method was used to compare trabecular bone density at the radius with the density at the lumbar spine in 29 female patients. The average vertebral trabecular BMD of L2-L4 correlated with the radial trabecular BMD ( $r=$ $0.758, \mathrm{p}<0.01$ ) (fig. 1). This relationship was valid for both the 15 patients who received chronic systemic GC therapy $(\mathrm{r}=0.657, \mathrm{p}<0.01)$ and the 14 patients who did not $(\mathrm{r}=0.790, \mathrm{p}<0.01)$.

\section{Discussion}

GC-induced bone loss probably occurs throughout the skeleton, but the rate of loss is different for trabecular and cortical bone. Previous reports have shown that the effects of GC on the skeleton are more marked in trabecular bone $[4,8,18,26]$, and fractures predominantly occur at sites that are rich in trabecular bone, such as the vertebral bodies $[1,4]$.

The findings in this report confirm that GC administration causes bone loss, and that bone loss increases with age. However, bone loss was most marked in cortical bone among elderly patients. The discrepancy between these results and those of previous studies $[4,8,18,26]$ may be due to the fact that the current patient sample was older, and to differences in the technology utilized.

Cortical BMD, even in the radius, correlated with the number of vertebral fractures $(p<0.01)$. This finding supports the concept that cortical bone is related to bone strength [13] and its weakness to fractures [14]. Thus, older patients who receive high cumulative GC doses, experience GC-induced bone loss not only of trabecular bone, but also of cortical bone. Therefore, even though GC-induced fractures predominantly occur at sites rich in trabecular bone and poor in cortical bone, it is believed that GC-induced cortical bone reduction increases vulnerability to fracture by weakening bone strength.

Trabecular bone mass at the distal radius and in the lumbar spine are correlated in healthy females using the

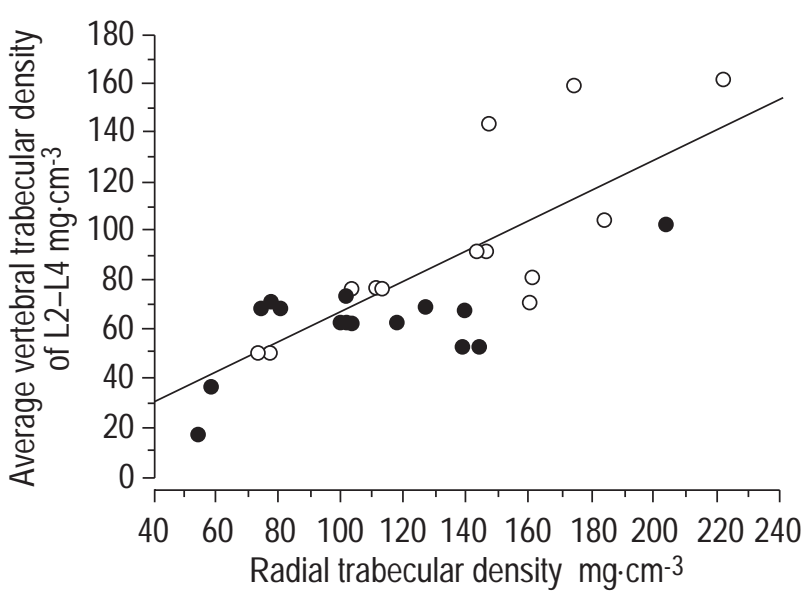

Fig. 1. - The correlation between the average vertebral trabecular bone mineral density (BMD) of L2-L4 and the radial trabecular BMD. The overall coefficient $(\mathrm{r}=0.758)$ indicates a significant correlation between vertebral trabecular BMD of L2-L4 and distal radial trabecular BMD in 29 female asthmatic patients $(\mathrm{p}<0.01)$. This correlation $(\mathrm{p}<0.01)$ was found in the 15 patients who received chronic systemic glucocorticoid $(\mathrm{GC})$ therapy $(\mathrm{O})(\mathrm{r}=0.657)$ as well as the 14 patients who did not $(\bigcirc)$ $(\mathrm{r}=0.790)$.
QCT method $[15,24]$. No previous study has examined whether this correlation is valid in patients who suffer GC-induced bone loss. Using DPA, VIllareal et al. [5] reported that bone loss due to GC therapy occurs at different rates at the femoral neck and the lumbar spine in asthmatic patients. Using SPA, ROzENBERG et al. [27] found that sex hormones affect bone mineral content differently at different sites.

Asthmatic patients, regardless of whether they received systemic GC therapy, displayed a high correlation between radial and vertebral trabecular BMD using the QCT method.

Axial and appendicular trabecular bone would not be expected to undergo bone loss in an identical manner, given the different site-dependent factors, such as weight bearing. The high correlation observed in this study indicates that axial and appendicular trabecular bone are probably affected similarly by similar metabolic factors, regardless of the location. The consistency of the relationship findings also suggest that $\mathrm{pQCT}$ on the radius can provide an assessment of the general condition of bone.

In conclusion, systemic glucocorticoid administration decreases the density of both trabecular and cortical bone. This effect is most pronounced in older patients. The cortical bone reduction contributes to the occurrence of glucocorticoid-induced fractures. Axial and appendicular trabecular bone appear to be similarly influenced. Confirmation of these findings requires a longitudinal study.

\section{References}

1. Adinoff AD, Hollister JR. Steroid-induced fractures and bone loss in patients with asthma. N Engl J Med 1983; 309: 265-268.

2. Kwong FK, Sue MA, Klaustermeyer WB. Corticosteroid complications in respiratory disease. Ann Allergy 1987; 58: 326-330.

3. LoCascio V, Bonucci E, Imbimbo B, et al. Bone loss in response to long-term glucocorticoid therapy. Bone Miner 1990; 8: 39-51.

4. Reid IR. Glucocorticoid osteoporosis-mechanisms and management. Eur J Endocrinol 1997; 137: 209-217.

5. Villareal MS, Klaustermeyer WB, Hahn TJ, Gordon EH. Osteoporosis in steroid-dependent asthma. Ann Allergy Asthma Immunol 1996; 76: 369-372.

6. Boulet LP, Giguere MC, Milot J, Brown J. Effects of long-term use of high-dose inhaled steroids on bone density and calcium metabolism. J Allergy Clin Immunol 1994; 94: 796-803.

7. Luengo M, del Rio L, Pons F, Picado C. Bone mineral density in asthmatic patients treated with inhaled corticosteroids: a case-control study. Eur Respir J 1997; 10: 2110-2113.

8. Ruegsegger P, Medici TC, Anliker M. Corticosteroidinduced bone loss. A longitudinal study of alternate day therapy in patients with bronchial asthma using quantitative computed tomography. Eur J Clin Pharmacol 1983; 25: 615-620.

9. Reid IR, Evans MC, Wattie DJ, Ames R, Cundy TF. Bone mineral density of the proximal femur and lumbar spine in glucocorticoid-treated asthmatic patients. Osteoporos Int 1992; 2: 103-105.

10. Eriksen EF, Vesterby A, Kassem M, Melsen R, Mosekilde L. Bone remodelling and bone structure. In: Mundy GR, 
Martin TJ, eds. Physiology and Pharmacology of Bone. Berlin, Springer-Verlag, 1993; pp. 67-109.

11. Ninomiya JT, Tracy RP, Calore JD, Gendreau MA, Kelm RJ, Mann KG. Heterogeneity of human bone. J Bone Miner Res 1990; 5: 933-938.

12. Vaughan J. The Physiology of Bone. Oxford, Clarendon, 1975 .

13. Keller TS. Predicting the compressive mechanical behavior of bone. J Biomech 1994; 27: 1159-1168.

14. Augat P, Reeb H, Claes LE. Prediction of fracture load at different skeletal sites by geometric properties of the cortical shell. J Bone Miner Res 1996; 11: 1356-1363.

15. Ruegsegger P, Anliker M, Dambacher M. Quantification of trabecular bone with low-dose computed tomography. J Comput Assist Tomogr 1981; 5: 384-390.

16. Ruegsegger P, Stebler B, Dambacher M. Quantitative computed tomography of bone. Mayo Clin Proc 1982; 57: 96-103.

17. Schaadt O, Bohr H. Bone mineral in lumbar spine, femoral neck and femoral shaft measured by dual photon absorptiometry with 153-gadolineum in prednisone treatment. Adv Exp Med Biol 1984; 171: 201-208.

18. Brandli DW, Golde G, Greenwald M, Silverman SL. Glucocorticoid-induced osteoporosis: a cross-sectional study. Steroids 1991; 56: 518-523.

19. Gatti D, Rossini M, Zamberlan N, Braga V, Fracassi E, Adami S. Effect of aging on trabecular and compact bone components of proximal and ultradistal radius. Osteoporos Int 1996; 6: 355-360.
20. Ruegsegger P, Durand E, Dambacher MA. Localization of regional forearm bone loss from high resolution compuputed tomographic images. Osteoporos Int 1991; 1: 76-80.

21. Wapniarz M, Lehmann R, Randerath $\mathrm{O}$, et al. Precision of dual X-ray absorptiometry and peripheral computed tomography using mobile densitometry units. Calcif Tissue Int 1994; 54: 219-223.

22. Guglielmi G, Gluer C, Majumdar S, Blunt B, Genant H. Current methods and advances in bone densitometry. Eur Radiol 1995; 5: 129-139.

23. Guglielmi G, Schneider P, Lang TF, Giannatempo GM, Cammisa M, Genant HK. Quantitative computed tomography at the axial and peripheral skeleton. Eur Radiol 1997; 7: S32-42.

24. Fujii Y, Chikawa T, Nakamura T, Goto B, Fujita T. Comparison of trabecular bone density at vertebral and radial sites using quantitative computed tomography. Osteoporos Int 1996; 6: 486-490.

25. Grampp S, Genant HK, Mathur A, et al. Comparisons of noninvasive bone mineral measurements in assessing agerelated loss, fracture discrimination, and diagnostic classification. J Bone Miner Res 1997; 12: 697-711.

26. Ruegsegger P, Durand EP, Dambacher MA. Differential effects of aging and disease on trabecular and compact bone density of the radius. Bone 1991; 12: 99-105.

27. Rozenberg S, Ham H, Bosson D, Peretz A, Robyn C. Age, steroids and bone mineral content. Maturitas 1990; 12: $137-143$. 